\title{
Supply Chain Management in the Context of Digitalization
}

\author{
Pavel Sizov
}

Ural State University of Economics, 620144 Ekaterinburg, Russia

\begin{abstract}
The article deals with the actual problems of supply chain management in modern conditions. A review of the references on the use of digital technologies in supply chain management has been carried out. The relevance of the use of automated systems in supply chain management has been shown. The author's methodological approach to the construction of information support for the network structure of supply chains has been proposed. Practical approbation according to the logical scheme for the selected research object has been demonstrated. The blocks of an automated control system for information support of the network structure of supply chains have been described.
\end{abstract}

\section{Introduction}

In recent years, the number of tasks associated with the processing of large amounts of data has been increasing in logistics systems, for the solution of which it is necessary to create automated information systems for managing logistics processes and introduce new digital technologies. Information technologies of the 20th century are now sufficiently being studied, which led to the transition to a new era of digital logistics. Digital technologies not only accompany and facilitate material processes, but there is a change in the use of human resources, and, as a consequence, the restructuring of their material, financial, information flows, which is reasonably presented in the work of Afanasenko I.D., Borisova V.V. "Digital logistics" [1].

It is important that the digital environment has its own infrastructure. At the same time, the possibilities of information and telecommunications facilities increase, unmanned vehicles appear, where control is $100 \%$ robotic [1].

Every year, even every month, the introduction of new technologies that increase the speed of data exchange is accelerating, and the bandwidth of the Internet is increasing. At the same time, costs are reduced due to logistic synchronization and timely exchange of information between service providers and trading partners [2].

With the introduction of modern systems, artificial intelligence can replace the investments. For example, a computer system that can efficiently plan inventory requirements will reduce the need to take inventory of reserve resources. The availability of flexible computing means allows participants in supply chains to dynamically model possible problems and solve them in the future [6]. 


\section{Materials and methods}

The study of modern Internet technologies, software, as well as issues of modeling and information support in the network structures of supply chains in the works of the authors [5], [6] proves that digital logistics should be based on a new generation of logistics applications based on web technologies who build collaboration and optimization using a central information logistics highway, which in turn provides transparency for all participants in logistics processes.

Supply Chain Management (SCM) is a concept that implements an integrated approach to the management and planning of information flows of business entities regarding products, raw materials, materials and services. Information is generated and transformed in logistics processes aimed at meeting the demand of end users. At the same time, the company must make maximum possible profit from its activities. This approach has been developed over time and has received practical application in supply chain management. The supply chain is a collection of warehouses, forwarders, manufacturers, distributors, trade enterprises that cooperate and interact in material, financial and information flows, as well as flows of services from sources of raw materials to the final consumer. The supply chain is a set of material processes and the corresponding information flows between the participants in the chain [2].

$\mathrm{SCM}$ is, in practice, a key concept in business process management for many organizations. First of all, such companies include large-scale networks of divisions and branches, between which material flows are moved, as well as the exchange of related information flows. These companies include logistics service providers, large industrial enterprises, trade and distribution networks, transport companies [8].

Supply chain management is the planning and management of all activities (in the supply chain), including sourcing and purchasing management, product transformation (processing) and management of all types of logistics activities.

The supply chain network structure model should be based on the principles of optimization of the following parameters:

- deviation of the actual execution of the order from the predicted one;

- influence of the human factor on the processes in supply chains;

- amount of stocks.

Of course, ideal models cannot be found in real conditions, since there will always be unaccounted for parameters of the external and internal environment. To adapt the model in real conditions, a comprehensive optimization process must be carried out, covering the following activities:

1. Creation of a network configuration of a logistics network, covering consumers, suppliers, resellers, focal company, etc. The more complex the structure, the more difficult it is to effectively manage it, but it should be borne in mind that a special simplification of the network structure is unacceptable, because such actions can lead to distorted results. When configuring the networks, including logistics, you can apply network planning methods.

2. Creation of integrated supply chains. In the process of interaction, participants in the network structure form a certain integration chain that provides the following synergistic properties:

- increased coordination and rhythm of the movement of the material flow;

- increasing the efficiency of planning, as a result of the intensification of information flows;

- reduction of transaction costs;

- cooperation and, as a consequence, intensification of information exchange between the participants in the chain; 
- increased flexibility as a systemic adaptation of the circuit to changing conditions of functioning.

3. Reengineering of the logistics network. In the process of dynamics of external and internal factors, such as the transformation of the demand structure, changes in the working conditions of suppliers, etc. there is a need to redesign the network.

4. Organization of the inventory management process in supply chains. Providing the ability to plan inventory throughout the integrated chain. [10]

The implementation of digital technologies in logistics systems worries many scientists. This problem was considered in their works by Afanasenko D.A., Borisova V.V., Gorsky D.V., Krasnoperova M.V., Kokurin D.I., Kupriyanovskaya Yu.V., Kupriyanovskiy V.P., Larin ON., Lysenko M.V., Lysenko Yu.V., Matveev V.V., Nemanova A.N., Rozhko O.N., Sergeev V.I., etc.

Gorskiy D.V. in "Conceptual foundations of supply chain management in e-commerce" indicates the relevance and need for the development of information systems in supply chain management, because it is a resource for reducing logistics costs for the process of goods distribution, which e-commerce provides without the involvement of commercial intermediaries and personnel in their traditional form. The introduction of information technology brings control in supply chains to a new level [11].

Krasnoperova M.V., Matveev V.V. in "Analysis of modern trends in the development of logistics infrastructure ..." express the opinion that for the buyer, as the end user of the product, the trend of introducing the Internet into logistics makes it possible to extract the transparency of the transportation process. He will be able to trace the point of departure of the product - whether the product is counterfeit or fake, he will be able to check if the conditions of transportation of the product have been violated. [12]

Nemanova A.N. in "An Integrated Approach to the Digital Transformation of Intermodal Container Transportation" considers the transition to digital business for logistics companies: "The main requirement of an integrated approach to the digital transformation of intermodal container shipping is to take into account the interaction of both internal and external factors that determine the formation of integrated benefits." [13]

Blockchain digital technology provides the formation and maintenance of a digital register of transactions with any assets in several places at the same time. Most often, the blockchain is referred to as monetary transactions, but this technology can be extended to any interconnected information blocks. In "Blockchain in Logistics", the authors point out that the main fundamental feature of the introduction of blockchain technology is the uninterrupted supply of information between partners and the improvement of the quality of processes at the present time. [14]

Despite the variety of digital technologies described above for their application in logistics systems and supply chain management, the issues and methods of building information systems for supply chain management remain poorly studied. Also, the questions of how exactly and at what stages to introduce digital technologies, when their implementation may not bring a positive effect [6], have also been little researched.

According to the authors [6], in order to create effective software for supply chain management, first of all, it is required to build information support for the network structure of supply chains. The task of building an information system arises for a specific object of research - an economic entity, functional area, etc. At the first stage, the form of the network structure of the supply chains of the selected object is analyzed and determined. Thus, using the proposed logical scheme (Fig. 1) and a systematic approach for analyzing and formalizing information flows, it becomes possible to build information support for the network structure of supply chains and solve specific problems for various logistics systems of the selected research objects [6]. 


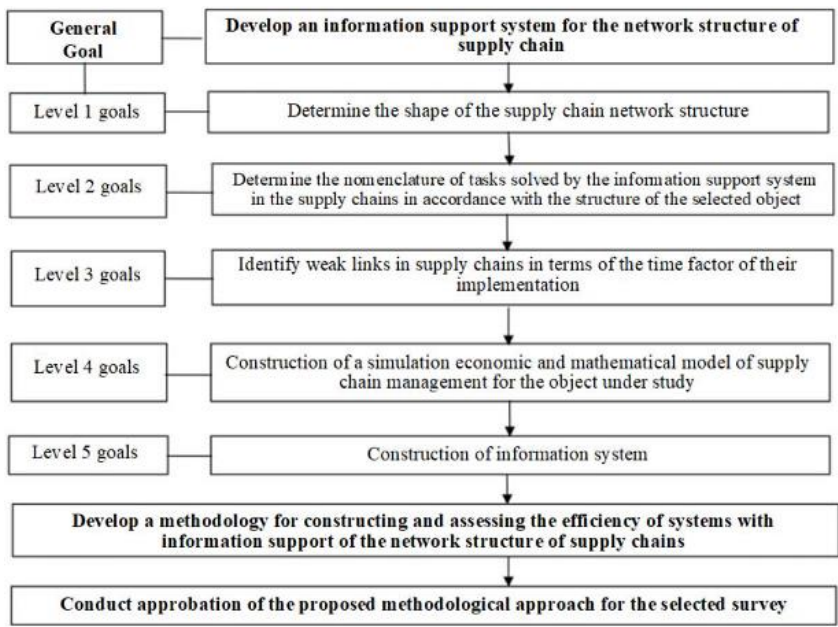

Fig. 1. Logical scheme for building an information support system for the network structure of supply chains

All elements of location, customer market, talent pool, quality of life requirements and government incentives will be taken into account when forming the logistics network. The analysis of the above factors will allow creating models that will give companies a deeper understanding of the choice of the structure of the logistics network [6].

\section{Results and discussion}

Using the proposed methodology for constructing information support for the network structure of supply chains, the authors carried out practical testing for GTC-GROUP transport and logistics company. Global Trade Consulting (GTC) Group is a group of companies providing a wide range of outsourcing services related to international transportation, customs clearance, banking support of transactions, legal support of transactions in foreign economic activity. Let us turn to the proposed methodological approach and logical scheme (Fig. 1).

1) General goal: To build an information support system for the network structure of supply chains for the selected object of GTC-GROUP research in order to solve specific applied problems that arise in the daily activities of the company.

2) Let's define the processes and the composition of the network participants for the selected research object.

GTC-Group - the provider of services (or goods) for the Customer

Customer company of services (or goods)

Marine agent in China - responsible for export clearance from China to the Russian Federation, for staging a container for loading goods, delivers it to the seaport and transfers it for further transportation

Air agent in China - responsible for export clearance and delivery of goods to the airport terminal for further transportation by air

Sea carrier - accepts a container at a port in China, loads onto a ship, transports to a seaport in the Russian Federation, transfers the container to an agent in a port of the Russian Federation

Agent in the port of the Russian Federation - formalizes customs transit, if necessary, participates in customs inspection, transfers the container for transportation across the territory of the Russian Federation by rail or on an automobile platform 
Railway carrier - delivers the container to the desired city of the Customer, transfers the container to a temporary storage warehouse (TSW)

$T S W$ - goods are placed for the procedure of customs clearance of declaration and release

Customs declarant - responsible for the preparation and verification of documents, registration of the customs declaration and submission to the customs authorities (as a rule, this is an electronic declaration center)

Customs of the Russian Federation - carries out customs control and customs release of goods

Removal of goods from TSW

Unloading and acceptance of goods at the Customer's warehouse in accordance with the accompanying documents

Signing of acts of services rendered (or documents of shipment of goods) between the Customer and GTC-GROUP

The customer shall ship the goods to the consumers of the next level or uses goods (or raw materials) for their own needs

In accordance with the described environment and processes, the authors schematically in the form of a directed graph built a diagram of the network structure of supply chains for the selected research object (Fig. 2).

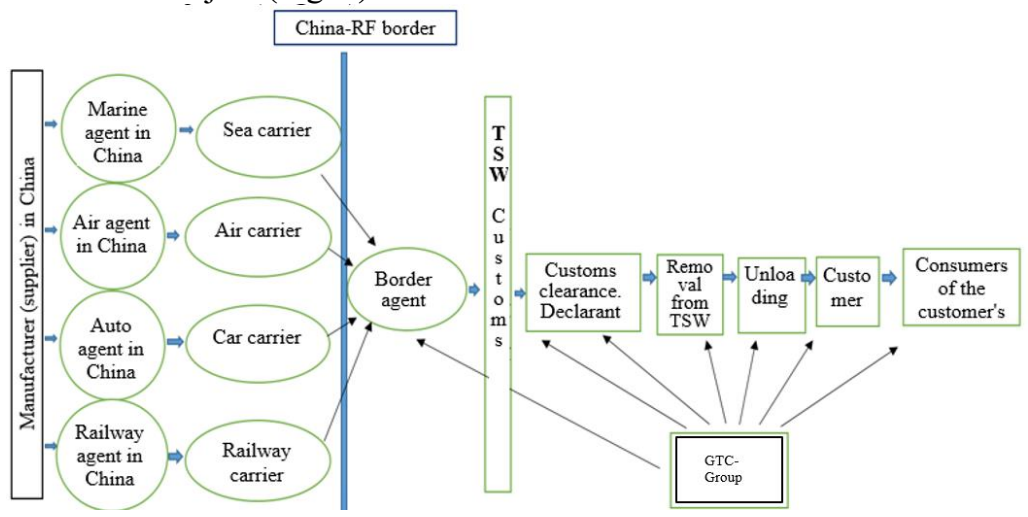

Fig. 2. Supply chain network structure for a transport and logistics company

3) We will identify weak links in supply chains in terms of the time factor of their implementation.

At each stage of the transportation process, there is a risk of a delay in time, or a situation arising when, in principle, it will be necessary to make changes to the route in case of the risk of a complete stop.

4) Let us construct a simulation economic and mathematical model of the network structure of supply chains for the selected research object.

Taking into account the sequence of processes and directed from link to link material and information flows, this scheme (Fig. 2) can be represented in the form of a directed graph.

According to the authors, when building a simulation model of the network structure of supply chains in actual conditions and forming the vertices of the graph, it is necessary to proceed from the following important conditions:

- Allocation of stages of processes, their sequence. Directed graph to identify the steps that must be completed before the next step occurs.

- Working with each stage as an independent subsystem that has an input and an output. In practice, this is a systematic automatic control or the installation of a responsible person, reporting rules for a responsible person. 
- Identification of bottlenecks, situational hazards in supply chains. What indicators do we monitor so that the supply chain does not stop. (For example, when supplying the necessary materials in a manufacturing facility, the bottleneck may be an "irreplaceable" employee who is sick). Perhaps unforeseen circumstances should be taken out in a separate item. Any force majeure situations can be taken into account here.

- The possibility of implementing SWOT analysis is a method of strategic planning, which consists in identifying the factors of the internal and external environment of the organization and dividing them into four categories: Strengths, Weaknesses, Opportunities, Threats.

Having identified the processes and participants in the supply chain network structure, it is proposed to introduce the following parameters:

SS - the total cost of carriage of goods, including all additional costs and customs clearance

$S_{p}$ - cost of transportation (services of agents and a carrier, depending on the route)

$T_{p}$ - total transportation time

$S_{t}$ - cost of customs clearance (registration of a declaration, payment of mandatory fees, duties, taxes)

$S_{o}$ - other services (services of loaders, agents, removal of a container from a temporary storage warehouse, storage at a temporary storage warehouse)

B - route safety (is there a risk of a complete stop on the route or loss of cargo. For example, during the COVID-19 pandemic, the border crossing in the Trans-Baikal Territory functioned, and the border crossing through Kazakhstan was closed, accordingly, a reorientation of cargo flows was required).

GR - border crossing speed (whether delays are possible. For example, certain border crossings or seaports are overcrowded, which significantly increases the processing time of goods and the registration of transit declarations.)

Thus, the total cost of transportation can be expressed by the following formula:

$\mathrm{SS}=S_{p}+S_{t}+S_{o}$

We introduce the function $\mathrm{F}\left(S_{p}, T_{p}\right)$ - the time and cost of transportation for different carriers on different routes

$\mathrm{F}\left(S_{p}, T_{p}\right) \longrightarrow \min -$ target optimization of the cost and time of transportation under the given constraints G... Gm

For example, limits can be set as follows: $S_{p}<3000 \$, T_{p}<14$ days

$\mathrm{F}\left(S S, T_{p}, B, G R\right) \longrightarrow \min$ - optimization of the cost and time of transportation, taking into account all additional costs, as well as taking into account the inherent risks of route safety and the speed of crossing the border between China and the Russian Federation.

To build a simulation model of the network structure of supply chains and to solve optimization problems, the authors used the theory of graphs and its mathematical apparatus. [4]

5) Creation of an information system. At the first stage, the general architecture of the system is formed - blocks, interfaces, software functions, mathematical apparatus for programming. The block of model indicators (p. 4), which can be entered as input parameters. These are, for example, risks, the cost of customs clearance, price offers from carriers on various routes, etc. Choosing a platform for programming - in this case, the $1 \mathrm{C}$ : Enterprise platform was chosen with additional implementation of web technologies and a number of modules were developed in the $\mathrm{C}++$ programming language. Analytical block - analysis, forecasts, recommendations. The block for solving optimization problems is the 
choice of a specific transportation route, carrier, agents and the formation of the total cost of transportation and the time cycle.

6) Solution of a specific applied problem. The customer contacted the company to arrange transportation from the Shanghai factory, China to the company's warehouse in Yekaterinburg, Russia, 21 tons of cargo (household napkins, a group of household goods), the volume of cargo is $53 \mathrm{~m} 3$. The transportation period should not exceed 40 days, the cost of transportation should be minimal. The client needs to offer the best transportation option.

The solution issued by the system within a few seconds: Sea transportation Ningbo-Vostochny, then railway transit Vostochny - Yekaterinburg Sortirovochny, auto removal of a container on a platform from a temporary storage warehouse to a warehouse in Yekaterinburg, cost \$2670, duration 36 days.

Analysis of all data and carrying out calculations in "manual mode" showed that this solution is indeed optimal under the given conditions. However, this analysis took about 2 hours by 2 employees of the company.

7) Scalability of the model and information support system. In the near future, it is planned to introduce new important indicators into the simulation model of the supply chain network structure, expand the capabilities of the analytical unit by introducing an automatic cargo tracking system, signaling in case of difficulties on routes, as well as a subsystem for dynamic analysis of routes for cargo that are already on the way. Implement a blockchain system, connect customers and contractors, carriers to the system, so that the process is controlled and transparent for all participants and any participant can have up-to-date information about the movement of cargo along the route.

\section{Conclusion}

Thus, the proposed methodology, logical scheme and the author's approach for building an automated information support system for the network structure of supply chains have shown their consistency in practical testing at a specific research object. In the future, the system allows you to dynamically enter new parameters into the model without significant changes as additional parameters of programmable functions.

Advances in digital technology allow organizations, with relatively small investments, to quickly improve efficiency in supply chain management, which can provide a competitive advantage in the marketplace. However, it is worth noting that the attractiveness of these technologies led to the fact that some companies began to hastily implement everything in a row, without having a verified system of tasks that must be solved by the introduction of a specific technology. Ultimately, such a choice can lead the digitalization project to a dead end. It must be admitted that the digital transformation of supply chains should be carried out in accordance with a well-considered algorithm of actions, conducted analysis and strictly following the list of planned activities. Companies that take this approach are more likely to benefit from digital promises.

It is also worth noting that when introducing modern digital technologies, security problems may arise, which were voiced by Natalya Kasperskaya at the forum on digital technologies - any modern technology has remote control, which creates the risk of a onetime restriction for users of this technology [7]. 


\section{References}

1. I.D. Afanasenko, V.V. Borisova, Digital logistics. Textbook for universities, 272 (2019)

2. Dan Gilmore, McHugh, Software, https://www.supplychainmarket.com/

3. E.S. Akopova, Y.V. Przhedetsky, N.V. Przhedetskaya, K.V. Borzenko, Marketing of Healthcare Organizations: Technologies of Public-Private Partnership, 89 (2020)

4. M.O. Asanov, V.A. Baransky, V.V. Rasin, Discrete mathematics: matroid graphs, algorithms, 288 (2001)

5. P.L. Sizov, Methodological approach to building an information system for supply chain management (2018)

6. P.L. Sizov, Z.B. Khmelnitskaya, Economics and entrepreneurship, 8(109), 1159 (2019)

7. Natalia Kasperskaya, Digital forum 2018 (2018)

8. N.S. Kireeva, Decision-making in supply chain management at the strategic level, Questions of economic structuring (2010)

9. A.G. Samoilova, Logistics (2014)

10. M.A. Zhuk, I.A. Tsyganova, Innovation and investment, 12 (2016)

11. D.V. Gorsky, Economic Sciences, 4(25) (2017)

12. M.V. Krasnoperova, V.V. Matveev, Bulletin of Udmurt University, 28 (2018)

13. N.A. Nemanova, Integrated approach to the digital transformation of intermodal container transport, Bulletin of research results (2019)

14. Yu.V. Lysenko, M.V. Lysenko, R.I. Garipov, Azimuth of scientific research: Economics and management, 8, 3(28) (2019) 